\title{
Is American Higher Education All That Bad?
}

\author{
Robert Weissberg
}

Published online: 25 March 2011

(C) Springer Science+Business Media, LLC 2011

Pessimism about the state of higher education is a venerable tradition. Socrates probably believed Aristotle to be a plodder wasting his time by observing plants and animals. Indeed, it's been my experience that whenever professors of a certain age gather for chit-chat, regardless of field and ideology, the conversation will inevitably turn to the poor intellectual quality of today's students, their sloth, the rampant cheating, grade inflation, the rise of empty calorie ideologically flavored majors and the ease by which the intellectually indifferent can graduate. Arum and Roksa's Academically Adrift only supplies a more scientific account of these oft-repeated depressing assessments.

Matters are, however, more complicated than just cataloguing student ineptitude. This is not to argue that all is well in the academy; all the complaints do reflect a depressing reality. Rather, professors who focus exclusively on students as the over-riding cause of our educational malaise over-simplify and thereby obscure more complicated issues bedeviling American higher education. Moreover, no guarantee exists that today's students can be prodded to perform better and pushing them harder may prove disastrous to those bemoaning their woeful inadequacy.

\section{How Much Brain Power Suffices?}

Assessments of contemporary higher education implicitly view it as if it were a factory turning out products essential for our national well-being and, as Academically Adrift shows, much of what falls off the assembly line is shoddy

\footnotetext{
R. Weissberg $(\varangle)$

99 Battery Place 28A,

New York, NY 10280, USA

e-mail: rweissbe@illinois.edu
}

merchandise. With this quality control mentality in place, gloom and doom are inevitable. Further add that our overseas rivals out-perform US students, especially in math and science so necessary to brain-powered modern economies. Nonetheless, the factory analogy may be inappropriate. The sky is not falling.

For one, it is unclear how much specialized top brain power the US requires to survive in a competitive world marketplace. This is a maddening empirical question and cannot be answered by assembling statistics showing that millions of undergraduates goof off and cheat. Progress need not arrive by armies of well-trained graduates overwhelming a problem. After all, it only took a single Newton to invent calculus and a few garage-based geeks to create Apple computers. To appreciate this point, imagine accrediting music schools and unhappily finding that most students were tone deaf. Yet, it is quite possible that a few outstanding graduates could supply the world's demand for concert pianists, opera singers and the like. The proportions of chaff to wheat may not be the relevant benchmark.

To demonstrate that thousands of students squander their college years guzzling beer and fail to graduate says nothing about whether universities are supplying sufficient intellectual talent. Better to scrutinize the job market and salaries or ask if our intellectual needs are being met by importing smart workers from overseas. If help wanted ads for computer engineer jobs run in the thousands, all offering sky high ever-escalating salaries, then it is clear that something on America's campuses is amiss. This does not, however, seem to be the case. The National Science Foundation regularly monitors America's scientific brain power and they do not find anything seriously wrong. One study reports that the number of scientists and engineer has recently increased sharply but relatively low levels unemployment still occur. In other words, since not every 
scientist or engineer can find a job when supply is rapidly expanding, we may even be producing a few too many. A 2008 NSF press release explicitly stated that we should not worry about the US filling jobs in science and the recent economic downturn may have expanded the pool of unemployed scientific talent. If one doubts America's capacity to satisfy the need for brains, just ask placement directors at many of today's Ph.D. program. It is an open secret that many of these programs, even in intellectually demanding fields suffer a glut of job candidates and many graduates find employment outside of their specialized training.

It is equally true that many jobs do not require much "book learning" and necessary skills can be acquired on the job. After all, somebody has to manage proliferating fast food restaurants etc. etc. and those who breezed through college unencumbered by serious learning maybe the ideal job candidate. A recent Bureau of Labor Statistics study illustrates that the American economy is, thankfully, unwilling to treat shoddy graduates as the real thing. Among other findings, it reported that in 1992119,000 waiters and waitresses had college degrees but by 2008 this figure had soared to 318,000 and this pattern was true in many other low-level occupations. In other words, the market may be self-correcting when it comes to assessing the value of empty calorie diplomas. A cynic might thus aver that American universities do improve workforce quality, top to bottom, albeit upping the intellectual ability of those taking food orders.

From the perspective of how much top talent is sufficient, the existence of indisputably first-rate institutions, the Cal Techs and MITs, may suffice despite existing in a sea of intellectual mediocrity. Moreover, even if these first-rate institutions could not supply the necessary brain power so vital to our future, this shortage may be beyond remediation given the supply of home-grown cognitive talent. We cannot assume that matters will improve, as reformers demand, if curriculums are made more rigorous, grading standards stiffened and all the rest; perhaps the US has already maxed out its supply of high IQ students so admitting more applicants to rigorous programs and turning the thumb screws is the equivalent of trying to squeeze blood from turnips.

The question of adequate home-grown brain power sooner or later raises the awkward (and politically incorrect) issue of demography. To be blunt, much of what transpires in today's universities, for better or worse, is far more sensitive to fertility and immigration patterns than decisions made by Deans about rewarding good teaching or attempting to deflate grades. The supply of brain power in the incoming freshman class is undoubtedly decisive when it comes to improving student performance. It is easy to hand out " $D$ 's" when the Admissions Office is overwhelmed by applicants with perfect
SAT scores and with this army knocking on the door, current enrollees quickly learn that sloth will not be tolerated.

The news regarding the talent pool is mixed and this should not be ignored when cataloguing the sorry state of American higher education. A parallel exists with expanding the number of professional sports franchises and the inevitable talent dilution, a reality that has brought multi-million dollar salaries to coddled mediocre athletes. In 1980 there were 1957 institutions of higher learning but by 2007 they had grown to 2675 and all were competing for tuition-paying bodies with a pulse. Meanwhile, today's credential mania has boosted the proportion of high school graduates seeking a college degree, from slightly more than half to two-thirds (and among blacks, the increase is substantially larger). One does not have to be a rocket scientist to connect the dots: continued institutional survival often means enrolling and retaining students who barely belong in college. So, rather than complain about academically indifferent students and gift grades, ire should be directed at proliferating colleges, their unwise generous admission standards and the federal government's willingness to finance mediocrity with need-based scholarships.

The well-known pattern of delayed marriage among the smart also has contributed to the dumbing down. Today's college classroom would be far different if high IQ women did not pursue professional careers requiring extra years of schooling and instead married early and had two or three children before age 25. But without this additional supply of smart kids, accommodating very ordinary students (plus a few affirmative action and legacy admits, plus athletes) becomes vital. Imposing draconian academic measures is pointless if those flunked are replaced by those with even less cognitive talent and worse work habits. It is thus rational, especially in today's enrollment driven academic environment, for professors to close their eyes and give passing grades to slackers who download their papers from the Internet. Professors may whine about their dreadful students, but getting rid of them by raising standards probably means fewer professors and who wants to risk being voted off the island?

But this thin talent pool has an antidote. Thanks to fortuitous waves of immigration that began in the mid1960s, namely the influx of knowledge-hungry Asians and a bit later, Russians, our domestic talent pool has expanded. For fans of top-flight American education, this flood has been a god-send though the legal change permitting it had zero to do with enhancing America's brain power. Visitors to elite research universities daily see that the best, most ambitious students in demanding technical fields are children of immigrants or themselves recent arrivals. Just walk around MIT, Cal Tech or Stanford and look at the faces and listen to student conversations. At the University of California, Berkeley, a study found that nearly $12 \%$ of the enrolled were foreign born while $14.5 \%$ had at least one parent born overseas. At New York City's elite public 
universities the influx of Asian and Russian students has similarly transformed institutions that nearly collapsed into, again, a stellar institution of higher learning that resembles an earlier era when knowledge hungry immigrant children created the "poor man's Harvard."

This adaptation to the shoddy quality of American undergraduates is perhaps most pronounced when compared to foreign graduate students recruited in fields requiring both exceptional intelligence and diligence. In 1966 when the US labored to send a man to the moon only $14.3 \%$ of the earned Ph.D.'s went to non-US citizens with a temporary residence; by 2003 the figure was a third and it seems to be rising. Post $9 / 11$ visa restrictions temporally slowed the craving but most recent statistics show that foreign graduate students in engineering and science are again flooding American graduate schools. For example, in 2006-7, the number of US citizens entering graduate programs in engineering increased by $1 \%$; the increase figure for foreign born students was $7 \%$. The ratio in the physical sciences was nearly identical, $1 \%$ increase among Americans versus $6 \%$ for those from overseas.

It is easy to treat these get-them-from-abroad statistics as yet more evidence on the sorry state of domestic intellectual talent and the ineptitude of our K-12 education but all the moaning and groaning does not say whether Academically Adrift is describing an intractable condition or a problem awaiting an available fix. But if I had to choose I'd put my money on the former - it's intractable. As somebody who has spent nearly four decades at prestige, research-oriented universities, much of the sloth that bedevils American higher education is, at least in my estimation, beyond remediation. You cannot beat base metal into silver, let alone gold. Imagine the outcome if a professor decided to "get serious." That is, require attendance, assign ample dense reading, give snap quizzes to ensure that the reading was read, demand immediate expulsion of cheaters and impose an old-fashioned " $\mathrm{C}$ " centered curve? This guarantees a rebellion among the school's "customers," especially for required gateway courses, and I'd guess that administrators would have a quiet talk with this hardnosed professor. If the course were an elective, its unsavory reputation would soon get out and facing a miniscule enrollment, the professor would be re-assigned to teaching introductory courses. Better to surrender to reality.

In the final analysis, then, when the distribution and supply of intellectual talent is calculated, and the institution insist on surviving and pay faculty, it makes perfect economic sense to tolerate beer-drinking undergraduates snoozing through Mickey Mouse courses taught by blasé faculty. To repeat, focusing on the proportion of good to bad students (not absolute numbers) is the wrong metric. Nevertheless, American higher education can be improved but cataloguing widespread student deficiency seeks a solution in all the wrong places.
Given our diagnosis, several changes immediately come to mind though all are too "controversial" to be implemented. None require torturing today's slackers. First, reduce the number of third and fourth tier colleges, perhaps by denying government financed loans and scholarships to their students, replace them with vocational schools teaching useful market skills-more electricians, fewer majors in "communication studies." Then toughen admission standards at elite schools by junking all soft criteria that dilute a school's intellectual talent, measures like affirmative action, athletic scholarships and admission based upon essays about overcoming hardship. An old British saying put it bluntly: train the best, shoot the rest.

Second, enact policies that encourage smart people to have more children. Though critics will immediately scream "Hitler" and "eugenics," this can entail little more than altering the tax code to cover more child-rearing expenses among the wealthy (who tend to be smarter). Third, open the door even wider to highly motivated, intellectually superior students from abroad. Have the Admission Office hire Chinese-speaking recruiters to entice smart kids to come to America to replace hung-over party animals. If we insist on home-grown students, alter immigration policy to give extra weight to those from well-educated families or those who otherwise demonstrate a high IQ. In other words, just install a merit-based system of higher education.

This is, of course, fantasy but it is a far superior fantasy than trying to get blood from turnips. More important, these suggestions, no matter how impractical to impose, forces critics of American higher education to confront awkward issues all too easily neglected when beating up inadequate, lazy students is so much easy fun.

\section{Is Critical Thinking a Cure for our Malaise?}

Underlying Academically Adrift is the belief that American universities have a responsibility to teach more than what the course syllabus demands. This "teach more than narrow book learning" is commendable and I couldn't agree more. But, going beyond "book learning" acknowledged, what should it be? One solid candidate might be called Calvinist virtues plus a dollop of social skills: learning to be punctual, being able to manage time, handle crises, tenacity in the face of formidable obstacles, restraining appetites and impulses, an ability to follow instructions, even a talent for cooperating with varied fellow student plus the social graces like properly using a knife and fork. All very sensible and scarcely needing much justification. No doubt, the once commonplace focus on these nonacademic virtues explained why prospective employers viewed the degree from a first-rate school, apart from any demonstrated book learning, as prima facie evidence 
of vocational worthiness - one would always show up, properly behave, work hard and get the job done on time.

For Arum and Roksa, however, traditional "Calvinist" virtues are irrelevant, perchance too old-fashioned. Instead they emphasize a knack for critical thinking measured by something called the Collegiate Learning Assessment (CLA) in which the students show up once and analyze materials presented to them which required 90 minutes of work. That many of these same students in all likelihood often skip class, day dream during lectures, neglect the assigned reading, and cut corners (including cheating) when not taking the CLA test seems to go unnoticed. It might be interesting to know how many CLA test-takers signed up but failed to arrive on test day.

A talent for critical thinking is the book's leitmotiv and a scan of the book found "critical thinking" mentioned some 87 times (searches for "work ethic," "diligence" and "hard work" found zero and "discipline" was used 13 times but only once in the sense of students needing "discipline" and that appeared in a quote). To be sure, the authors are aware that their CLA measure is open to question but their review of criticism largely address testing per se or CLA measurement validity. The centrality of critical thinking in a college education is only asserted, often by merely quoting others who just reiterate the consensus. Nor is it clear exactly how many jobs require critical thinking as a condition for vocational success. Critical thinking is now the Apple Pie and Motherhood of modern college educators and, ironically, the passion for critical thinking goes unexamined. According to the Wikipedia entry on the topic, a 1972 study of 40,000 faculty members by the American Council on Education reported that $97 \%$ of the respondents indicated the most important goal of undergraduate education is to foster students' ability to think critically.

Personally, I am a great fan of "critical thinking" and always tell my graduate students on the first day of class that this will be stressed in my lectures and my take-home essay exams explicitly encourages it. Over the years former students have occasionally returned to thank me for their experience with these exercises in connecting dots in non-obvious but analytically rigorous ways. Many recall specific examples. "You really made me think," is what they say.

Burgeoning popularity and my own affection aside, however, it is unclear why this trait should be so central in how students approach college. Nor is it self-evident that critical thinking can be taught to all but the very best students (the Wikipedia entry on critical thinking briefly cites several empirical studies skeptical of colleges being able to impart this skill). I strongly suspect that skill at critical thinking is closely related to IQ and given IQ distributions, many students will just never get it. Based on Arum and Roksa's own data regarding academic disen- gagement, a better case could be made for re-invigorating a Calvinist work ethic-always attending class, paying careful attention, doing the required reading and resisting distractions like excessive drinking. After all, applying critical thinking first requires showing up etc. etc. If students were to embrace a strong work ethic many of the problems documented in Academically Adrift would undoubtedly vanish. If endemic sloth is the chief culprit, promoting critical thinking is the wrong medicine.

For me, critical thinking is probably best employed as a pedagogical tool used by the instructor to illuminate the nonobvious versus training students in this technique. It has been my experience in following classroom discussions and reading their essays where they are enticed to think critically, that this enterprise just wastes valuable class time. Yes, a tiny few may show flashes of insight when the materials are laid before them (as in the CLA) and guided to challenge assumptions, but the grade-savvy are far more inclined to just parrot back the instructor's insights. It is the autonomous use of critical thinking that is, supposedly, so important, not its display when the instructor provides all the necessary ingredients. To repeat, my experience is that while students can learn from it, very few will ever become expert practitioners.

Moreover, an ability to think critically about a given topic presupposes an enormous amount of relevant background knowledge seldom known to undergraduates or even graduate students. A knack for abstract reasoning and logical reasoning is also required, abilities seldom found outside of top school. In the way of illustration, my graduate course on elections dwells extensively on how the US winner-take-all, geographically-based arrangement encourages centrist political parties. I compare major US parties to what occurs in nations using proportional representation in terms of incentives, history and legal rules. I further discuss the purpose of elections and their cultural component. This is, at least in my estimation, a tour de force exercise in connecting multiple dots to produce a quite new (at least for students) insight about American politics. Students seem to appreciate the lecture but giving it requires endless backtracking to describe countless simple political facts (e.g., different types of majorities, the legal status of political parties, how parliamentary systems work and on and on). Nearly all of this background material is totally new to my students, all of whom are graduate students in a selective program. In other words, before you can connect numerous dots in nonobvious, enlightening ways, you have to know many, many dots, and most students know only a tiny few.

The moral of this story is that critical thinking is not a pathway to knowledge unless there is a substantial prior acquisition of extensive information. At least in my field (political science) proficiency in critical thinking requires years of reading dull tomes, debating issues with colleagues 
anxious to criticize and, best of all, writing books and scholarly papers to disentangle all the complexities. This is boring, often frustrating hard work and will never be undertaken without a strong work ethic. It is bizarre to insist that a lazy, ill-informed 20-year old student can, to use two components of the Wikipedia definition of critical thinking, be "both willing and able to evaluate one's thinking" and "thinks open-mindedly within alternative systems of thought, recognizing and assessing, as need be, their assumptions, implications, and practical consequences."

Let me put it this way. Decent universities even with less than brilliant students and ordinary faculty can strengthen the work ethic. We know how to terrorize students and, rest assured, students will immediately react to a reign of terror. But, do we really know how to teach critical thinking if students are reluctant to do the demanding prior work? Critical thinking may be best taught after a reign of terror and this should be the reformer's chief mission.

I would further add that bringing critical thinking to a classroom populated by uninformed students may inadvertently exacerbate academic insufficiency. Contrary claims aside, it will dumb down education by imposing huge opportunity costs. Through examples students can readily learn that knowing "mere facts," the very building blocks of future insight, is secondary to interpreting what little they know to draw personally satisfying conclusion. It has been my experience, and I'd guess many other professors would agree, that these "critical thinking" discussions tend to be vacuous and resemble dormitory BS sessions. The tip-off to this fluff is the incidence of "insights" that begin with "In my opinion..." or "I feel..." and the paucity of supporting hard evidence. Learning, if you can call it that, degenerates into back and forth weak arguments. Perhaps their principal value is to fill up class time, give students the satisfaction of having their voice heard while relieving the instructor of providing structured lectures. It is no wonder why many educators love it-it sure beats arduous preparation.

But it may get worse. Exercises in critical thinking can over-emphasize the critical in critical thinking. In the hands of an instructor pushing a political agenda, teaching critical thinking is a license to attack the status quo by exposing its alleged hidden assumptions, an ideologically driven search and destroy mission so to speak. Especially where students lack intellectual sophistication, this is remarkably easy. To return to my own teaching about election systems, critical thinking makes it a snap to "demonstrate" that the US election system is inherently "biased" against racial minorities, women and the poor while its reliance on expensive campaigns empowers the wealthy. While some students might rightly object to this "insight" but they are unlikely to prevail given the instructor's deeper knowledge and, most importantly, power over grades. Or, if a conservative were in charge, critical thinking can "demon- strate" how our circus-like election system encourages pandering to the poor brings higher taxes, bloated government and staggering debt so as to satisfy parasites living off public largess. Regardless of ideological slant, this approach is certainly more exciting than explicating boring election law.

\section{Some Cause for Optimism}

It is easy to understand why so many professors become discouraged with today's students. Who can keep the fire alive after reading their atrocious exams or looking out over a sea of blank faces or students more interested in texting and reading e-mail. It's enough to drive a person to drink or, better yet, write therapeutic books documenting this ineptitude.

The reality, however, is more upbeat. If we ignore that ratio of good to bad students, American higher education is performing well. Top schools produce first-rate graduates, even in the grueling sciences, and what we cannot manufacture at home, we import from overseas. Yes, many "graduates" may be semi-literate and innumerate but the post college market largely cures this defect- they become waiters and waitresses, not rocket scientists. It also may be futile to prod these slackers since they are performing as well as we can expect in light of their modest cognitive talents and seemingly intractable slovenly work habits.

Never forget that these hoards of mediocre youngsters help put bread on the table for thousands of professors. Yes, we suffer their stupidities but at the end of the month, the paycheck is there. Perhaps this explains the infatuation with pushing critical thinking - it can make learning painless fun for those who hate boring lectures, but most of all, it will not cull the dummies from the herd and thereby shrink enrollments. To appreciate this inconvenient truth about sustaining high enrollments regardless of quality, imagine higher education consisting of only the brightest. In terms of supplying America's intellectual needs it would be identicalperchance superior - to what now occurs but the number of academic jobs would decline sharply and who can predict where the unemployed wannabe professors would go? Perhaps like actors waiting for the big break, Ph.D.'s would wait on tables until retirement or death opened a teaching position. Job announcement would now attract thousands of applicants, not the hundreds as is common today. Armies of dull, lazy students are both a problem and a valuable economic resource. Be careful what you wish for.

Robert Weissberg is Professor of Political Science, Emeritus, University of Illinois-Urbana and currently Adjunct Professor of Politics, New York University. Recent books include Political Tolerance, The Limits of Civic Activism, Pernicious Tolerance and Bad Students, Not Bad Schools. 